\title{
Bacterial Profile and Antibiogram of Hospital-Acquired Pneumonia and Ventilator-Associated Pneumonia Patients in ICU of Raden Mattaher Hospital Jambi
}

\author{
Sotianingsih, Samsirun H, Lipinwati \\ Department of Clinical Pathology, Faculty of Medicine, Jambi University/Raden Mattaher Hospital, Jambi, Indonesia. E-mail: \\ sotianingsih@yahoo.com
}

\begin{abstract}
Pneumonia is defined as an inflammation of the lungs caused by microorganisms (bacteria, viruses, fungi, parasites). This research aimed to determine the pneumonia-causing bacteria along with the sensitivity and the antibiotic resistance test. This research was a descriptive study with samples of ICU pneumonia patients at Raden Mattaher Regional Hospital during the study period. All samples were consecutively selected. Samples for blood culture were incubated in the BactAlert device, whereas the sensitivity test was then performed using Vitex instruments. Sputum was previously enriched with BHI media and then cultured on culture media, and sensitivity test with the Vitex instruments was carried out. Of the 354 ICU patients during the study period, 30 patients (11.8\%) had pneumonia, but only 19 patients could undergo sputum culture. Five of 19 patients were infected with Gram-positive bacteria, and 14 patients were infected with Gram-negative bacteria. The most commonly found bacteria were Klebsiella pneumonia (36.84\%), followed by Acinetobacter baumanii (21.05\%) and Pseudomonas aeruginosa (10.53\%). Gram-negative bacteria obtained from sputum culture in this study were resistant to almost all antibiotic groups, especially Penicillin, Cephalosporin, Quinolone, and Tetracycline groups. Gram-positive bacteria obtained from sputum culture in this study were resistant to the penicillin antibiotic. The most commonly found bacteria were Klebsiella pneumonia (36.84\%), followed by Acinetobacter baumanii (21.05\%) and Pseudomonas aeruginosa (10.53\%). The bacteria cultured from the sputum showed multidrug resistance mainly to the Penicillin and Cephalosporin antibiotic. This research data can be used to consider the treatment of pneumonia Patients to decide more appropriate therapy.
\end{abstract}

Keywords: Hospital-acquired pneumonia, ventilator-associated pneumonia

\section{INTRODUCTION}

Pneumonia is defined as an inflammation of the lungs caused by microorganisms (bacteria, viruses, fungi, parasites). Pneumonia is frequently found in hospitalized patients. Pneumonia can be divided into Community Pneumonia (CAP) or Hospital Acquired Pneumonia (HAP). Also, when associated with mechanical ventilation, it is called Ventilator-Associated Pneumonia (VAP). ${ }^{1}$ Hospital-acquired pneumonia is pneumonia which occurs only 48 hours after admission to the hospital, whereas VAP can occur 48 hours after endotracheal intubation. ${ }^{2}$ Mortality of pneumonia patients in Asia according to the study is relatively high and ranges from $25-58 \%{ }^{3}$

The ideal therapy for pneumonia is the use of definitive antibiotics; however, bacteria culture and antibiotic resistance testing take much time; therapy can be started using empirical broad-spectrum antibiotics. By recognizing the microbial pattern in the hospital and selecting to use correctly, especially in the initial phase of the disease, the treatment of pneumonia is expected to be more productive.

\section{METHODS}

This research was a descriptive study with samples of ICU pneumonia patients at Raden Mattaher Regional Hospital from January to December 2018. All samples were consecutively selected. The patients or family members were asked for written consent to participate in the study. Research permission was obtained from the Health Research Ethics Committee of the Raden Mattaher Regional Hospital, Jambi, with number 1241/UN21.6/LT/2018.

The diagnosis of nosocomial pneumonia was made based on criteria from Infectious Diseases Society of America and the American Thoracic Society, including the onset of pneumonia, which occurred 48 hours after being hospitalized and 
excluded from all infections with incubation happened at the time of hospital admission. The diagnosis of nosocomial pneumonia was made based on a chest X-ray with new or progressive infiltrates. It was added to two of the following criteria: body temperature $>38^{\circ} \mathrm{C}$, purulent secretions, and leukocytosis.

All sputum samples were taken for sputum culture. Sputum culture was carried out on BHI media and incubated for 24 hours at $37^{\circ} \mathrm{C}$. If there was bacteria growth, the bacteria were transferred to Mac Conkey and Blood agar to enable visualization of bacteria. Bacteria were identified as Gram-positive and negative by Gram staining. Identification of bacterial species and antibiotic sensitivity tests were carried out with Vitek2 (bioMérieux).

Of the 354 ICU patients during the study period, there were 30 patients (11.8\%) with pneumonia, but only 19 patients could undergo sputum culture. The age of the patient ranged from 16-90 years, with a median value of 51 years. Male and female patients were accounted for 13 (68.42\%) and 6 (31.58\%) people, respectively. Ventilator-associated pneumonia occurred in 10 patients (52.63\%), while HAP occurred in 9 patients (47.37\%). A total of 10 patients (52.63\%) died, and nine patients (47.37\%) were discharged from the ICU due to clinical improvement. The length of stay ranged from 1-35 days, with an average of 11.459 .58 days.

During the sputum culture of 19 patients, five patients were infected with Gram-positive bacteria, and 14 patients were infected with Gram-negative bacteria (Table 1 and 2). The most commonly found bacteria were Klebsiella pneumonia obtained from 7 patients (36.84\%) followed by Acinetobacter baumanii obtained from 4 patients (21.05\%) and Pseudomonas aeruginosa obtained from 2 patients (10.53\%).

Gram-negative bacteria obtained from sputum culture in this study were resistant to almost all antibiotic types, especially those from the Penicillin, Cephalosporin, Quinolone, and Tetracycline groups. The best antibiotic sensitivity was obtained from Amikacin (42.85\%), Cefoperazone/Sulbactam (28.57\%), and Meropenem (28.57\%).

Gram-positive bacteria obtained from sputum culture in this study were resistant to the penicillin group of antibiotics. The best antibiotic sensitivity was obtained from Linezolid and Vancomycin, with a sensitivity of $100 \%$ for both.

\section{RESULTS AND DISCUSSION}

The results of this study indicated that Gram-negative bacteria caused greater cases of HAP and VAP compared to Gram-positive bacteria. This was in line with recent studies showing that Gram-negative bacteria, especially Pseudomonas aeruginosa, Acinetobacter baumanii, Haemophilus influenzae and Enterobacteriaceae (Klebsiella pneumoniae, E.coli, Enterobacter species, Serratia species, Proteus species, etc.) were responsible for $50 \%$ to $80 \%$ cases of HAP in intensive care room (Figure 1). ${ }^{4}$

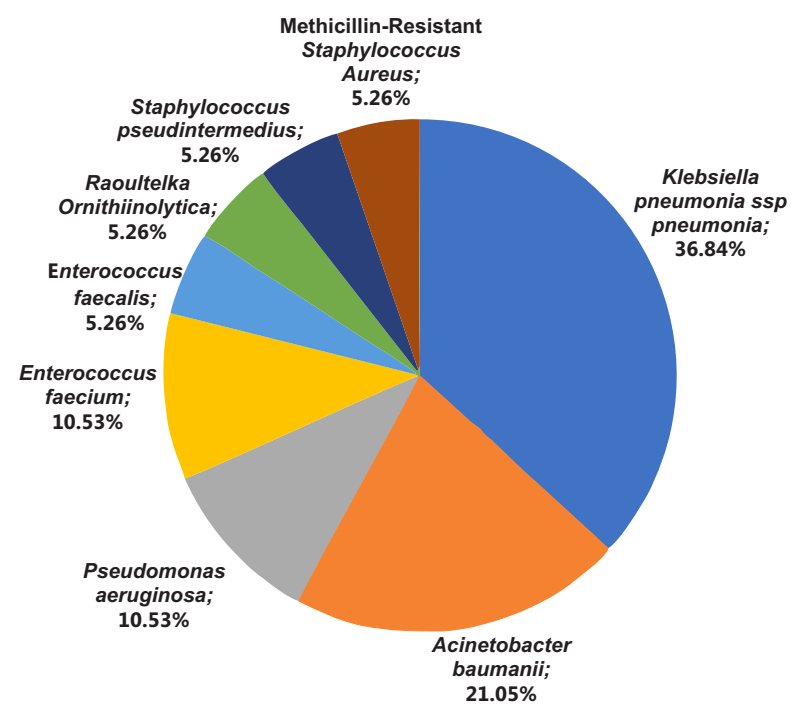

Figure 1. Bacteria found in the sputum of patients with pneumonia at Raden Mattaher Hospital, Jambi

Klebsiella pneumonia is known as one of the microorganisms, which commonly causes nosocomial infections, especially pneumonia, and has a high level of antibiotic resistance, especially to the $\beta$-lactam group. Research at Sanglah Hospital also found that K.pneumoniae was the most common Gram-negative bacteria in the sputum culture of patients with pneumonia. ${ }^{5}$ K.pneumoniae are encapsulated and non-motile Gram-negative bacteria that are widely found in soil, water surfaces or even medical equipment. K.pneumoniae was originally thought to be an opportunistic bacterium that causes infections in immunocompromised patients; however, recent studies have shown the development of hypervirulent bacterial strain that causes severe infections. K.pneumoniae can encounter antibiotics by expressing Extended-Spectrum $\beta$-Lactamase (ESBL) and has even been able to encounter Carbapenem by utilizing Cabapenemase. ${ }^{6}$ Extended-spectrum $\beta$-lactamase is a $\beta$-lactamase, which causes resistance to Penicillin and first-, second- and third-generation Cephalosporins and Aztreonam. ${ }^{7}$ According to CLSI, ESBL can be observed based on the resistance 
patterns of Cefotaxime and Ceftazidime antibiotics. ${ }^{8}$ This research finding results showed that all K.pneumoniae cultures were resistant to Cefotaxime and Ceftazidime and were categorized as ESBL. This might affect the high mortality in this study.

Acinetobacter baumanii is a non-fermenting, non-forming spores, non-motile and aerobic Gram-negative coccobacillus. A.baumanii lives ubiquitously in nature and can be found in soils and water. A.baumanii can also be found in hospital food, ventilator equipment, pillows, mattresses, tap water, and another area in the hospital. A.baumanii infection is most commonly found in the airways, and it generally only affects patients with low immune status. Reports of antibiotic resistance to A.baumanii continue to emerge through various mechanisms, such as AmpC cephalosporinase, topoisomerase DNA mutations, aminoglycoside modified enzymes and other mechanisms. ${ }^{9}$

Pseudomonas aeruginosa is an aerobic Gram-negative bacillus that is commonly found in soil and water. P.aeruginosa can spread from patient to patient through droplets or contaminated food and drinks. P.aeruginosa is an opportunistic bacterium with the ability to cause severe infections, especially in cancer, cystic fibrosis, and burn-injured patients. ${ }^{10}$ P.aeruginosa can also cause endocarditis, pneumonia, and urinary tract infections. $P$.aeruginosa is known as one of the bacteria with a high level of resistance, especially to Aminoglycosides, Quinolone, and $\beta$-lactam, even the World Health Organization has stated that P.aeruginosa is resistant to Carbapenem and is listed as one of three bacterial species requiring the development of new antibiotics. ${ }^{11}$ This study also showed a high level of resistance of $P$.aeruginosa to antibiotics from the aminoglycoside, quinolone, and $\beta$-lactam groups (Table 1 ).

This research found Enterococcus faecalis and Enterococcus faecium as the most common Gram-positive bacteria. Enterococcus is an anaerobic, facultative Gram-positive coccus bacterium with negative catalase that does not form spores. Based on Lancefield grouping, Enterococcus

Table 1. Antibiogram of Gram-negative bacteria resistant

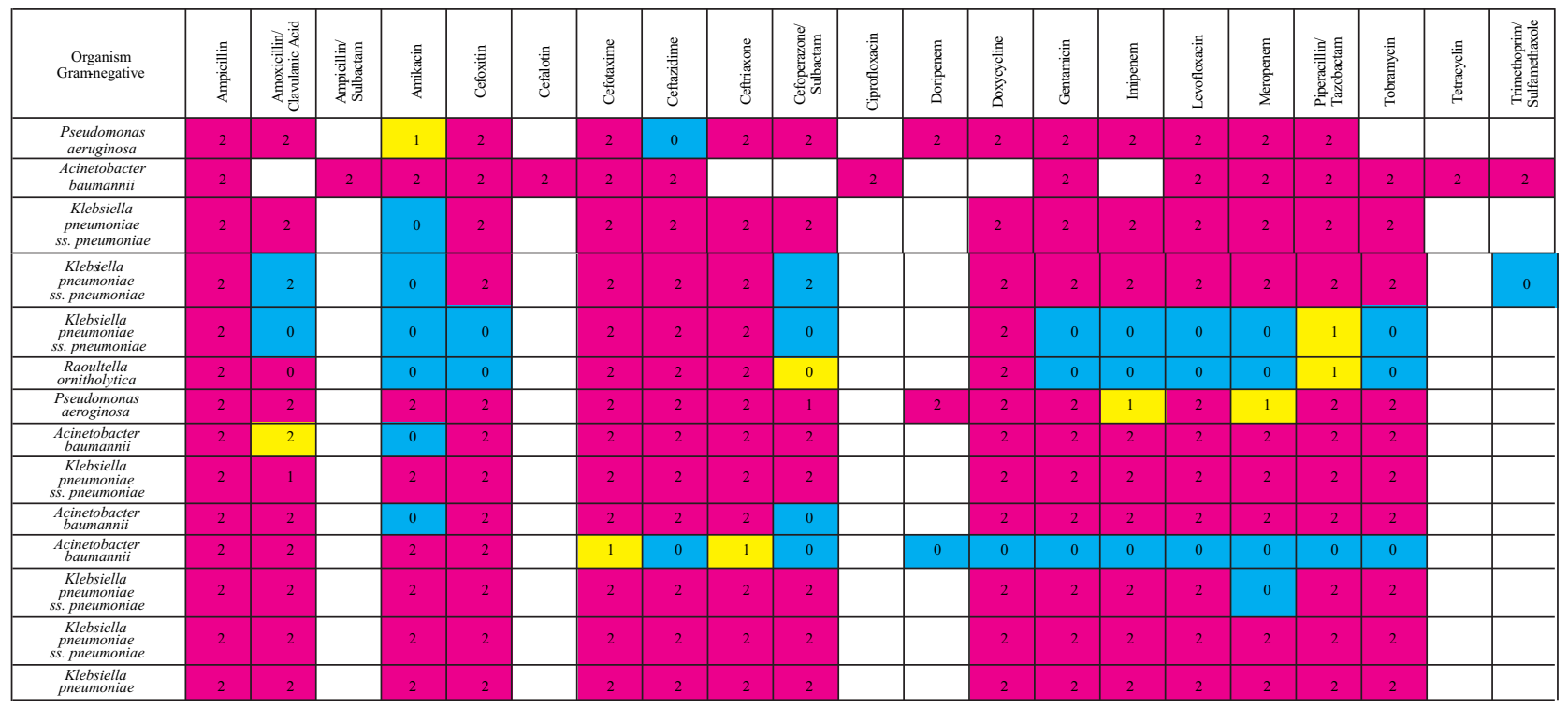

$0=$ sensitive; $1=$ intermediated; 2 = resistent

Table 2. Antibiogram of Gram-positive bacteria

\begin{tabular}{|c|c|c|c|c|c|c|c|c|c|c|c|c|c|c|c|c|c|c|c|c|c|c|c|c|c|}
\hline $\begin{array}{c}\text { Gram-positive } \\
\text { bacteria }\end{array}$ & 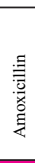 & 悬 & 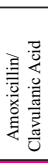 & 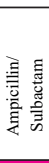 & 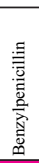 & $\begin{array}{l}\text { 竞 } \\
\text { 产 } \\
\text { 鄫 }\end{array}$ & 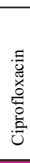 & 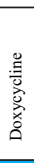 & $\begin{array}{l}\text { 总 } \\
\text { है } \\
\text { 壱 } \\
\text { 点 }\end{array}$ & 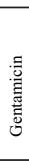 & 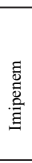 & 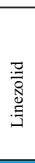 & 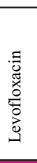 & 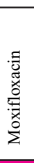 & 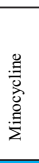 & 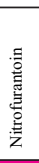 & 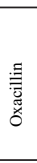 & 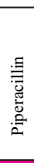 & 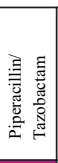 & 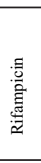 & 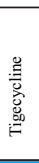 & 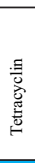 & 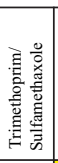 & 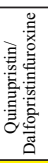 & 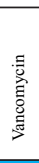 \\
\hline $\begin{array}{c}\text { Enterococcus } \\
\text { faecalis }\end{array}$ & 2 & 2 & 2 & 2 & 2 & 2 & 2 & 0 & 2 & & & 0 & 2 & 2 & 0 & 2 & & 2 & 2 & & 0 & 0 & & 1 & 0 \\
\hline $\begin{array}{c}\text { Enterococcus } \\
\text { faecalis }\end{array}$ & 0 & 0 & 0 & 0 & 0 & 2 & 0 & & 1 & & 0 & 0 & 0 & 0 & & 0 & & 0 & 0 & & 0 & 2 & & 2 & 0 \\
\hline $\begin{array}{c}\text { Staphylococcus } \\
\text { pseudintermedius }\end{array}$ & & & & & 2 & 0 & 0 & & 0 & 0 & & 0 & 0 & 0 & & 0 & 0 & & & 0 & 0 & 0 & 0 & 0 & 0 \\
\hline $\begin{array}{l}\text { Staphylococcus } \\
\text { aureus (MRSA) }\end{array}$ & 2 & 2 & 2 & 2 & 2 & & & & 0 & 0 & 2 & 0 & 0 & 0 & & 0 & 2 & 2 & 2 & 0 & 0 & 2 & 0 & 0 & 0 \\
\hline $\begin{array}{c}\text { Enterococcus } \\
\quad \text { faecalis }\end{array}$ & 2 & 2 & 2 & 2 & 2 & 2 & 2 & & 2 & 0 & & 0 & 2 & 2 & & 1 & & 2 & 2 & & 0 & 2 & & 0 & 0 \\
\hline
\end{tabular}

$0=$ sensitive; $1=$ intermediated $; 2=$ resistent 
belongs to the Streptococcus group D. Enterococcus is usually found as normal flora in the digestive tract of humans and animals. It can sometimes be found in the oral cavity in small amounts. Enterococcus is usually an opportunistic bacterium and can cause urinary tract infections, intra-abdominal infections, bacteremia, and endocarditis. In a rare condition, Enterococcus can cause pneumonia in patients with low immune systems who receive broad-spectrum antibiotics. Enterococcus infection was initially thought to originate from normal flora of patients; however, further research, especially in hospitals, showed that the primary mode of transmission between patients occurs through the hands of medical personnel. Enterococcus has also been reported to be a strain of bacteria that is resistant to Vancomycin. ${ }^{12}$

Staphylococcus aureus, especially Methicillin-resistant Staphylococcus aureus (MRSA), is known as one of the most common causes of nosocomial pneumonia and is estimated to be responsible for $20-40 \%$ cases of HAP or VAP. S.aureus is a Gram-positive coccus which usually forms grape-like clusters with positive catalase and positive coagulase test. S.aureus is commonly found on the surface of human skin and mucosa. ${ }^{13}$ Transmission of MRSA infections mainly occurs due to contact with contaminated hands or clothing (Table 2). ${ }^{14}$

\section{CONCLUSIONS AND SUGGESTIONS}

The prevalence of pneumonia in the Intensive Care Unit of Raden Mattaher Regional Hospital was approximately $11.8 \%$, with merely 19 patients underwent sputum culture. The bacteria that commonly caused pneumonia in this study were mainly Klebsiella pneumoniae and Acinetobacter baumanii, which were resistant to $\beta$-lactam, Quinolone, and Carbapenem.

Pneumonia can be prevented by applying a VAP bundle and to preventing the misuse of antibiotics. It was also suggested to use empiric antibiotics, which can act against a wide range of pneumonia-causing microorganisms.

Further suggestions are as follows: Improvement of hand hygiene of health staffs by implementing six-step hand washing at five washing times according to WHO recommendations; Maintenance of patients' oral hygiene, head-up position, nebulizer, and chest physiotherapy to minimize the incidence of bronchopneumonia; Improvement of CSSD's ability to maintain the stability of medical devices, including the use of plasma techniques which can sterilize rubber and plastic.

\section{REFERENCES}

1. Mackenzie G. The definition and classification of pneumonia. Vol. 8, Pneumonia (Nathan QId), 2016; 14.

2. Kalil AC, Metersky ML, Klompas M, Muscedere J, Sweeney DA, et al. Management of adults with hospital-acquired and ventilator-associated pneumonia: 2016 clinical practice guidelines by the Infectious Diseases Society of America and the American Thoracic Society. Clin Infect Dis an off Publ Infect Dis Soc Am, 2016; 63(5): e61-111.

3. Chawla R. Epidemiology, etiology, and diagnosis of hospital-acquired pneumonia and ventilator-associated pneumonia in Asian countries. Am J Infect Control, 2008; 36(4): S93-100.

4. Cilloniz C, Martin-Loeches I, Garcia-Vidal C, San Jose A, Torres A. microbial etiology of pneumonia: Epidemiology, diagnosis and resistance patterns. Int J Mol Sci, 2016; 17(12): 2120.

5. Budayanti NS, Suryawan K, Iswari IS, Sukrama DM. The Quality of sputum specimens as a predictor of isolated bacteria from patients with lower respiratory tract infections at a tertiary referral. Front Med, 2019; 6(April): 1-6.

6. Paczosa MK, Mecsas J. Klebsiella pneumoniae: Going on the offense with a strong defense. Microbiol Mol Biol Rev, 2016; 80(3): 629-61.

7. Paterson DL, Bonomo RA. Extended-spectrum beta-lactamases: A clinical update. Clin Microbiol Rev, 2005; 18(4): 657-86.

8. Poulou A, Grivakou E, Vrioni G, Koumaki V, Pittaras T, et al. Modified CLSI Extended-Spectrum $\beta$-Lactamase (ESBL) confirmatory test for phenotypic detection of ESBLs among Enterobacteriaceae producing various $\beta$-lactamases. Bourbeau $P$, editor. J Clin Microbiol [Internet]. 2014; 52(5): 1483 LP - 1489. Available from: http://jcm.asm.org/content/52/5/1483.abstract. [accessed 12 July 2020]

9. Hartzell JD, Kim AS, Kortepeter MG, Moran KA. Acinetobacter pneumonia: A review. MedGenMed, 2007; 9(3): 4.

10. Matos ECO de, Matos HJ de, Conceição ML, Rodrigues YC, Carneiro IC do RS, Lima KVB. Clinical and microbiological features of infections caused by Pseudomonas aeruginosa in patients hospitalized in intensive care units. Rev Soc Bras Med Trop, 2016; 49(3): 305-11.

11. Pang Z, Raudonis R, Glick BR, Lin T, Cheng Z. Antibiotic resistance in Pseudomonas aeruginosa: Mechanisms and alternative therapeutic strategies. Biotechnol Adv [Internet]. 2019; 37(1): 177-92. Available from: https://doi.org/10.1016/j.biotechadv.2018.11.013. [accessed 14 July 2020]

12. Agudelo Higuita NI, Huycke MM. Enterococcal disease, epidemiology, and implications for treatment. 
Table 1. Antibiogram of Gram-negative bacteria resistant

In: Gilmore MS, Clewell DB, Ike $\mathrm{Y}$, et al., editors. Enterococci: From commensals to leading causes of drug resistant infection [Internet]. Bosto. In. 2014.

13. Woods C, Colice G. Methicillin-resistant Staphylococcus aureus pneumonia in adults. Expert Rev Respir Med [Internet]. 2014 ;8(5):641-51. Available from: ht tps://doi.org/10.1586/ 17476348.2014.940323. [accessed 14 July 2020]

14. Andersen LP, Nielsen X. Methicillin-resistant Staphylococcus aureus transmission: Unrecognised patient MRSA carriage. Dan Med J, 2015; 62(4): A5047. 